\title{
Impacts of New Modes of Instructions for Nanotechnology Education within Engineering and Science Programs
}

\author{
Dr. Maher E. Rizkalla, Indiana University-Purdue University, Indianapolis
}

Maher Rizkalla received his Ph.D. in Electrical and Computer Engineering from Case Western Reserve University in 1985. From January 1985 to September 1986, he was employed as a Research Scientist at Argonne National Laboratory, Argonne, IL, and an Assistant Professor at Purdue University Calumet until September 1986. Then, he joined the Department of Electrical and Computer Engineering at IUPUI where he is now Professor and Associate Chair of the Department. His research interests include solid State devices, VLSI signal processing, and electromagnetics. He is a senior member of IEEE and a PE registered in the State of Indiana.

\section{Dr. Mangilal Agarwal, Indiana University-Purdue University Indianapolis}

Mangilal Agarwal received his B.E. degree in Electronics and Communication Engineering from Osmania University (Hyderabad, India) in 1998, and the M.S. and Ph.D. in Engineering from Louisiana Tech University (Ruston, LA) in 2002 and 2004, respectively. Upon receiving his Ph.D. degree, he was employed by Louisiana Tech University, as a Postdoctoral Research Associate, followed by appointments as Research Staff and Research Assistant Professor at the Institute for Micromanufacturing, the largest campus-wide interdisciplinary research institute. Currently the Interim Director of the Integrated Nanosystems Development Institute (INDI), Associate Director for Research Development at Office of Vice Chancellor for Research (OVCR), and Adjunct Associate Professor in the Electrical and Computer Engineering Department at Indiana University - Purdue University Indianapolis (IUPUI) (Indianapolis, IN), his main responsibilities include the development of interdisciplinary research and education initiatives.

\section{Dr. Sudhir Shrestha, Indiana University - Purdue University Indianapolis}

Sudhir Shrestha received his B.E. in Electrical and Electronics Engineering from Kathmandu University, Nepal, in 2003 and his Ph.D. in Engineering with Nanotechnology and RF/Wireless emphasis from Louisiana Tech University, LA, in 2009. From 2009 to 2011, he was a Postdoctoral Research Associate at the Integrated Nanosystems Development Institute (INDI) at Indiana University - Purdue University Indianapolis (IUPUI), Indianapolis, IN. Since 2011, he is an Assistant Research Professor in the Department Electrical and Computer Engineering at IUPUI. His current research interests include nanotechnology, renewable energy, sensors, wireless sensing systems, and nanotechnology education.

\section{Dr. Hazim A El-Mounayri, Indiana University Purdue University, Indianapolis}

Dr. El-Mounayri received his PhD in 1997 from McMaster University (in Canada) in Mechanical Engineering, He is currently an associate professor of Mechanical Engineering, the co-director of the Advanced Engineering and Manufacturing Laboratory (AEML) at IUPUI, and a senior scientist for manufacturing applications at Advanced Science and Automation Corp. He co-developed the Advanced Virtual Manufacturing Laboratory for Training, Education and Research (AVML), an innovative e-learning tool for educating students and training the next generation workforce in sophisticated technology and its underlying theory. Dr. El-Mounayri's research focus is in advanced manufacturing, including nano- machining modeling using techniques such molecular dynamics and multiscale simulations, and realization using AFM. Dr. El-Mounayri has worked as consultant for and conducted R\&D for a number of local companies in the areas of CAD/CAM, CNC machining, and process development/improvement. Dr. El-Mounayri is a member of ASME, ASEE, and SME. He has published over 60 technical papers in renowned peer-reviewed journals and technical conferences in his field and gave presentations at various national and international conferences.

Dr. Kody Varahramyan, Indiana University - Purdue University Indianapolis 
Kody Varahramyan received his Ph.D. in Electrical Engineering from Rensselaer Polytechnic Institute in 1983. From 1982 to 1992 he was with IBM Microelectronics, conducting research and development in the realization of advanced semiconductor technologies. From 1992 to 2008 he was with Louisiana Tech University (Ruston, LA), where he was the Entergy/LP\&L/NOPSI Professor of Electrical Engineering, in recognition of his teaching and research contributions in the microsystems and nanotechnology areas. From September 2000 to June 2008 he was the Director of the Institute for Micromanufacturing (IfM), where, from 1992, he had contributed to the growth and development of the Institute, including through planning and setting up of laboratory resources and facilities, development and implementation of major sponsored research efforts, and realization of academic courses and curricula, on the science and engineering of materials, processes, and devices for the realization of micro/nanoscale systems. Since July of 2008, he has been the Vice Chancellor for Research at IUPUI, where he has been responsible for the advancement of research and scholarly activities, including interdisciplinary research programs that address important national and global needs. 


\title{
Impacts of New Modes of Instructions for Nanotechnology Education within Engineering and Science Programs
}

\begin{abstract}
A new multidisciplinary nanotechnology track was developed and delivered within Electrical \& Computer Engineering (ECE) and Mechanical Engineering (ME) programs. This track features new modes of instructions that integrate knowledge from engineering and sciences research projects into academic curricula. A team of faculty from both the School of Engineering and Technology and the School of Science has developed course materials and laboratory components. A total of 12 credit hours, in addition to research modules, compose a nanotechnology track curriculum within ECE and ME programs. This paper presents the educational objectives of the program, and in particular new modes of instruction used in the delivery of the coursework. These modes include the integration of knowledge, just in time delivery, multidisciplinary components, and undergraduate research. The nanotechnology courses offered in this program also serve as elective courses within traditional engineering programs. Assessment was accomplished by comparing satisfaction data from students enrolled in traditional courses to those participating in these new elective courses. The nanotechnology track shows an average satisfaction of 4.2 out of 5.0 as compared to the traditional departmental electives that averages 3.8 out of 5.0. Assessment data also reveal the positive impact of these instructional modes compared to those utilized in traditional engineering coursework. This paper presents these new delivery approaches and the sample research projects included within the newly introduced nanotechnology courses.
\end{abstract}

\section{Introduction}

Nanotechnology is a rapidly advancing field that shows promise in solving current science and technology challenges through the innovative materials, processes/devices, and their applications. Nanomanufacturing including self-assembly has become an important tool in developing nanoscale devices applicable in medicine, electronics, and energy. Nanomaterials such as carbon nanotubes, graphene, quantum dots, and nanoparticles are of particular interest in sensor technologies, electronics, and other devices to meet the US industrial challenges. The multidisciplinary nature of this emerging field encompasses both engineering and science disciplines through the integration of physics, biology, chemistry, and engineering (biomedical, electrical, mechanical, and materials) [1-4]. Therefore, a class of multidisciplinary students, when assimilated into a nanotechnology course, enhances students' ability to work productively in a collaborative setting with colleagues from various disciplines; and the integration of engineering/science knowledge and the learning experience of the students in a meaningful way. The goals of this new program are to design a multidisciplinary research based curriculum for nanotechnology track that prepares students to enter the local, national, and global workforce and become leaders of research and development in industry, businesses, and academia in the emerging era of nanotechnology.

Engineering 2020 concerns designing an engineering curriculum that grows to meet or exceed current and future demands [5]. Developing engineering curricula and educating students to meet the industry challenges were presented previously [6-8]. This paper presents the impacts of new 
modes of instructions for nanotechnology education within engineering and science programs. The new curricula integrate knowledge from different engineering and science disciplines with applications in electronics, telecommunication, energy, and life sciences and incorporate technologies, processes, sciences, and applications of nanotechnology. Students pursuing this nanotechnology track should complete 12 credit hours in addition to 3- one credit research modules. These credit hours are counted towards their BS degrees as both the ECE and ME department allow up to 18 credits of elective courses and the multidisciplinary nanotechnology courses designed for this track fit well among the allowed list of elective courses for all majors.

\section{Nanotechnology Track}

IUPUI Purdue School of Engineering and Technology has developed and implemented a program that incorporates a research-based academic nanotechnology track. The Integration of Nanotechnology in Engineering Curriculum program (the IUPUI “INEC"), defined by the nanotechnology track, is integrated into the established degrees including Bachelor of Science in ECE and ME degree programs. INEC brings together students/faculty collaborative research and academic teams to provide undergraduate students with curricula that incorporate both research and education in nanotechnology. A diagram that depicts the ideals of the implemented nanotechnology track integrating research components into the Courses, Senior Design, and Laboratory Sessions is shown in Fig. 1.

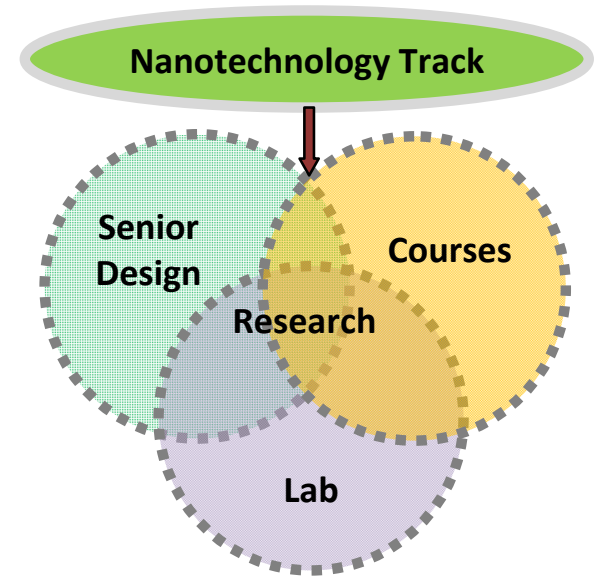

Fig. 1: Schematic diagram representing ideals of the nanotechnology track, which include Courses, Senior Design, Laboratory Sessions, and Hands-on Research activities.

The nanotechnology track implemented at IUPUI is a powerful pedagogical approach to comprehensively integrate nanotechnology into the curricula within the engineering degree programs. Throughout the four years, ECE and ME programs are focused on the various elements of nanotechnology. During the freshman year, students from these programs are introduced to various modules of nanotechnology through Theme Learning Communities (TLCs). In the first semester to form TLC, a cohort of 25 students are concurrently enrolled by the IUPUI Registrar to introductory courses in engineering, Introduction to Engineering (ENGR 196), Introduction to Engineering Profession (ENGR 195), and Fundamentals of Speech Communications (COMM R110) linked with the theme of nanotechnology (shown in Table I). The high quality delivery of the IUPUI's TLC programs has a great impact on the developed 
nanotechnology track. IUPUI's TLC program was awarded the 2008 Outstanding Student Retention Program Award by the Educational Policy Institute.

TABLE I: An example for the TLC within a semester, the cohort is enrolled in the following courses.

\begin{tabular}{|l|l|l|}
\hline \multicolumn{2}{|l|}{} & \multicolumn{2}{|c|}{ Freshman Year } \\
\hline ENGR 195 & $\begin{array}{l}\text { Thtroduction to } \\
\text { Engineering } \\
\text { Profession } \\
\text { and to campus resources. The course is designed to help } \\
\text { students develop essential communication, critical thinking } \\
\text { and time-management skills needed for collaborative } \\
\text { techniques used in engineering practice. Discussions include } \\
\text { study in electrical engineering, computer engineering, } \\
\text { mechanical engineering, and bioengineering. New } \\
\text { discussions include information of nanotechnology track and } \\
\text { how it connects to various science and engineering } \\
\text { professions in academia and industry. }\end{array}$ \\
\hline ENGR 196 & $\begin{array}{l}\text { Introduction to } \\
\text { Engineering }\end{array}$ & $\begin{array}{l}\text { The course will introduce definition of nanoscale and } \\
\text { applications of nano-materials, -devices, and -systems in } \\
\text { energy, medicine, defense, information technology, and } \\
\text { consumer products. }\end{array}$ \\
\hline COMM & $\begin{array}{l}\text { Fundamentals of } \\
\text { Speech } \\
\text { Communications }\end{array}$ & $\begin{array}{l}\text { This course introduces students to principles of persuasion to } \\
\text { master clarity of oral and written ideas. The new module } \\
\text { will include assignments that critically examine and develop } \\
\text { well-researched arguments about the value of } \\
\text { nanotechnology and its future applications and development } \\
\text { in various scientific fields. }\end{array}$ \\
\hline
\end{tabular}

In addition to the nanotechnology modules integrated into the freshman engineering, new interdisciplinary sophomore-, junior-, and senior-level nanotechnology-based courses are introduced within the curriculum for students in the nanotechnology track. These new courses serve as technical electives for the traditional ECE and ME degree programs keeping the same overall required credit hours. The curriculum of this track is rich in hands-on experiences in order to prepare undergraduate students for graduate programs and the industrial workforce. New introductory-level courses (Introduction to Nanotechnology \& Applications and Micro/Nanoscale Measurements \& Characterization Systems) offer students a basic understanding of fundamental concepts, key instrumentation and equipment, and processes used in the fabrication and characterization of nanoscale devices, materials, and systems. Building on these concepts, senior-level Nanosystems Principles and Integrated Nanosystems Processes and Devices courses focus on the system-level and provide students with in-depth knowledge.

The two senior-level courses Nanosystems Principles and Integrated Nanosystems Processes and Devices were developed and introduced sequentially in the Fall 2009 and Spring 2010, and have been offered every fall and spring semester. These courses were designed to build on basic 
concepts from physics and chemistry by integrating knowledge from ME, ECE, and Biomedical Engineering (BME). Students from ECE, ME, BME, Physics, and Chemistry disciplines are enrolled in these multidisciplinary, cross-listed courses. The participation of the students in Nanosystems Principle Course Fall 2010 is shown in Fig. 2. A total of five faculty members from both engineering and sciences collaborated in developing and teaching these courses.

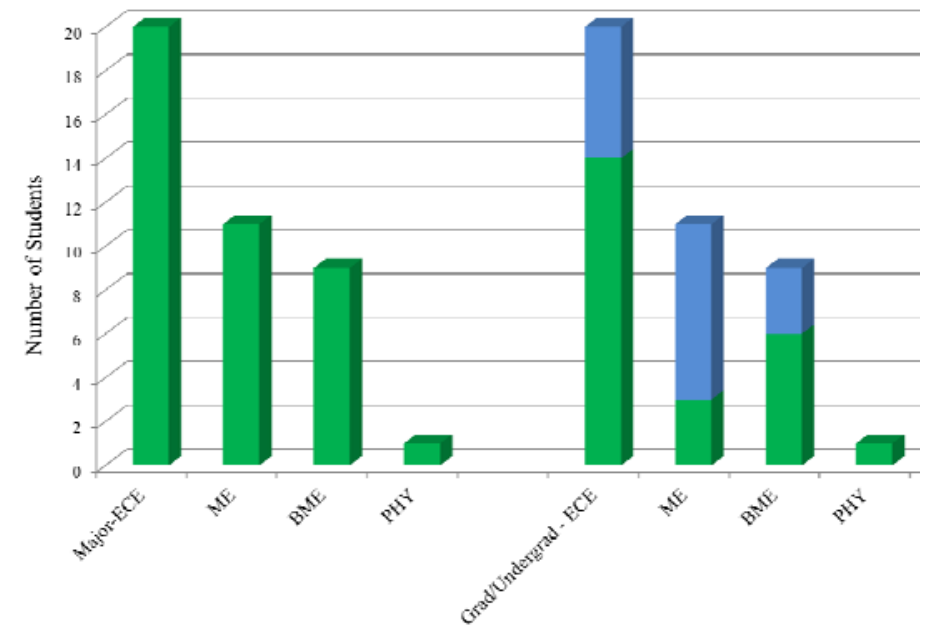

Fig. 2: Student participation in Nanosystems Principles based on discipline (Fall 2010). On Grad/Undergrad bars, the green colored (bottom) part represents number of graduate students and blue colored (top) part represents number of undergrdaute students.

These developed nanotechnology track courses also incorporate research term papers to widen the knowledge and understanding of the students into the emerging fields of nanotechnology. Term papers improve writing and research skills of the students based on key elements including: a thorough survey of the literature on the subject; an in-depth understanding of phenomena related to the subject; and an innovative analysis of possible solutions based on students' theoretical studies. In the two courses offered in Fall and Spring since 2009, Nanosystems Principles and Integrated Nanosystems Processes and Devices, term paper topics were chosen from cutting-edge fields of nanotechnology such as, nanotechnology employment in future vehicles, in quantum computers, for solar renewable energy, for automotive safety applications, and in drug delivery. The term papers also include an end of the semester poster presentation in a formal poster session. The poster session had a great positive research and learning impact on all students. Faculty members from both science and engineering schools were invited to attend and communicate with the students about the outcomes of their term paper and engage them in understanding of the topic.

\section{New Modes of Instructions}

\subsection{Just in Time/Only as Needed Delivery}

Just in time/only as needed delivery is a powerful mode of instruction for a multidisciplinary team teaching where different instructors (experts in their given field) introduce students to specific engineering/science components throughout the course. This mode was utilized in application courses that introduce theory "just in time" for the purpose of applications discussion. In such courses, instead of going in depths for the various theories from various 
courses, the application course introduces the theory just in time for the purpose of these applications. These methods of instruction were selected and have been used before to produce courses that motivate students to learn by making knowledge relevant to the task at hand. Just in time delivery introduces the science components only as needed at the appropriate time to guarantee smooth transition of the course application. Therefore, the concept of "just in time" delivery refers to the process of delivering lectures just in time for immediate applications. It minimizes time lag between learning and applying. With this instructional delivery mode, students learn something with a promise that you will need this later in the course. It was accomplished through the proper delivery sequence of the course components. For instance, science faculty prepares students for the theory and physics before the electrical engineering faculty introduces the students to the nanotechnology device section of the course. The only-asneeded selection of course contents eliminates the selection of topics that are interesting but devoid of practical applications. This concept is found to be appropriate to applications courses, where the focus is the applications and the science and engineering theories are covered to serve the application.

\subsection{Integration of Knowledge}

Integration of knowledge is not the same as project-oriented studies, but refers to the process of taking seemingly unrelated knowledge, such as knowledge of digital signal processing methods, solid state devices/design techniques, and microprocessor controllers and applying all three in an experiment or on a project. In traditional courses, students pursue a narrow topic deeper and deeper, and the knowledge is self-integrating. The concept of integration of knowledge is different from pre-requisite course/materials; rather it is a combination of science and engineering knowledge into a new area that benefits the science community. For instance, the integration of quantum mechanics, solid state devices, and cell biology, into nanoscience assembly and devices can lead to a new application that tackle many of the research issues that has never been addressed before. Likewise, knowledge from materials, fluid mechanics, thermodynamics, chemistry, computer programming, electromagnetics, and energy are all integrated into the new curricula. For example, knowledge of materials physics that provide means of varying resistivity of carbon nanotube from various gaseous compounds applied to develop a sensor device. The change in resistance may be detected via instrumentation procedures taught in the laboratory sections. The device section of the course covers methods of detecting frequency shift using nanodevices. The combination of these concepts from different courses or course sections provide methodology of applying nanotechnology materials into a gas sensor device and is a good example of integration of knowledge utilized in the presented models. In addition, a faculty member can supervise students for the device aspects; transmitting/receiving antennas with spectrum analysis for detecting frequency shift with 10 $\mathrm{MHz}$ over $2.4 \mathrm{GHz}$ carrier frequency, while other faculty may supervise on physics, chemistry, microelectronics, instrumentations, and other aspects of the project. Integration of knowledge is common in multidisciplinary programs. In the developed track, students from various disciplines

were introduced to new science and engineering concepts that are not covered in traditional curricula. 


\section{Research/Project Portfolio Curricula}

The assembly of multidisciplinary instructor and student teams has enhanced the quality of undergraduate research thereby making the transition from undergraduate to graduate programs natural and part of the culture. Involvement of undergraduates in research has taken various forms:

- Research shadowing of MS and PhD students coupled with hands-on learning and simulation

- Summer research opportunities

- Internships

- Senior design and capstone projects

- Research poster sessions and oral presentations

- National conferences

- Publications

In the poster session, students present their research work at the school conference hall, where faculty members, post-doctoral fellows, industrial representatives, and other graduate students attend and participate in the discussions with the presenting students. The poster presentation sessions are managed and organized at the level of national and international conferences.

The newly developed track provides three modules of research-based courses in three years, in addition to the team-based capstone design project that students must pursue during their senior year. Details on these two components are given below.

Senior Capstone Design Project: In this course, all ECE and ME students are required to perform a two-semester project that incorporate design components from various courses throughout the curricula. This course assists students with design methodology, the consideration of alternative solutions, and project planning in engineering design. Oral presentation and report writing are required for this course. For students in the nanotechnology track, requirements are the same, but an emphasis will be placed on nanotechnology (e.g. safety, reliability, economics, and aesthetics on nanosystems, nanoelectromechanical systems, nano-optical systems, nanomaterials/devices for renewable energy applications).

Research Modules in Nanotechnology: Research modules are designed to attract students to the INEC program and encourage the pursuit in graduate studies following the completion of their Bachelor of Science degrees. The following are new research modules that nanotechnology track students will pursue:

- Research modules are combined into one comprehensive research project that students may start working on it during the sophomore year and continue until the senior year.

- Research modules may include more than one research project within the three years: sophomore, junior, and senior year.

- Research modules may be linked with graduate students' research work to learn about research hypotheses, assumptions, limitations, simulation tools, and use of nanotechnology equipment for the research projects. 
As indicated above the research modules are within existing courses in the curriculum, and are not new courses. The only difference with this track is that these courses were used for research projects in nanotechnology. They can also be replaced by Internship from industry if the nature of the job is related to nanotechnology engineering or sciences. To engage nanotechnology track students in research, Integrated Nanosystems Development Institute (INDI) [9] in partnership with the Center for Research and Learning (CRL) [10] at IUPUI offers research programs such as Multidisciplinary Undergraduate Research Institute (MURI), and Undergraduate Research Opportunities (UROP), and Diversity Scholars Research Program (DSRP) [11].

\section{Recruitment Activities}

To recruit students for the new tracks, IUPUI Nanotechnology Discovery Academy Summer Camps [12] for high school students and teachers, high school visitation and presentation, and research partnership programs have been implemented.

IUPUI's Nanotechnology Discovery Academy (INDA) Summer Camps: Three week-long summer camps for high school students and teachers are conducted every year. The camp provides an overview of the field of nanosystems, covering materials, processes, and devices, resulting in nanosystems, and their use in a broad range of applications, with special emphasis on nanoenergy and nanomedicine. Building on the goal of conducting cutting-edge research generating discoveries that can be translated into practical applications, our intent is to provide a rich experience to students, which contribute to the foundation they need in order to become successful in their education and professional pursuits. Students work daily with world-renowned faculty at INDI laboratories in partnership with the CRL. This week-long summer day camp provides a unique opportunity for students to explore the interdisciplinary field of nanotechnology, which is becoming an essential part of science, engineering, medicine and many other disciplines. Students are exposed to several different resources including: cleanroom, nanoassembly, micro/nanofluidics, nanoscale measurements, and computational resources. Through INDA, a week-long summer workshops is also offered to high school teachers within the State of Indiana, introducing them to the state of the art laboratory and materials. This has resulted in growing knowledge of nanotechnology education and research activities at IUPUI and within the surrounding community.

High School Visitations and Presentations: Every Year INDI members conduct number of high school visitations and presentations. INDI members have also offered presentations and question/answer session at various high schools about the future of the nanotechnology career.

\section{Assessment Results}

\subsection{TLC Freshman Cohort}

The survey data within the Freshman Engineering cohort is shown in the Table II with comparative assessment results between nanotechnology cohort within the TLC (25 students) and the traditional undergraduate students taking other sections. The score of 5 represents "strongly agree" and a score of 1 represents "strongly disagree". Both the surveyed groups were from the same pool of students except that the nanotechnology cohort was in the TLC program. 
The higher level of knowledge about nanotechnology for the TLC group was because of the learning during the semester in the program.

TABLE II: Course Survey within the Nanotechnology-TLC Freshman Cohort (25 Students) Compared with the Traditional Undergraduate Class.

\begin{tabular}{|l|c|c|}
\hline \multicolumn{1}{|c|}{ Survey Questions } & $\begin{array}{c}\text { Nanotechnology } \\
\text { Cohort }\end{array}$ & $\begin{array}{c}\text { Traditional } \\
\text { Undergraduate } \\
\text { Class }\end{array}$ \\
\hline $\begin{array}{l}\text { I have a good understanding of what nano- } \\
\text { technology is }\end{array}$ & 4.44 & 2.90 \\
\hline $\begin{array}{l}\text { I believe knowledge of nanotechnology will benefit } \\
\text { me in the future: }\end{array}$ & 4.22 & 2.90 \\
\hline $\begin{array}{l}\text { I am aware of society issues that arise from the use } \\
\text { of nanotechnology: }\end{array}$ & 3.95 & 3.55 \\
\hline $\begin{array}{l}\text { Doing the project increased my understanding of } \\
\text { nanotechnology (Non TLC was pursuing a another } \\
\text { course project, ECE 196 project }\end{array}$ & 4.27 & 2.19 \\
\hline $\begin{array}{l}\text { Visiting the nanotechnology lab has given me a } \\
\text { better understanding of the research in this area }\end{array}$ & 4.33 & N/A \\
\hline $\begin{array}{l}\text { Working on nanotechnology paper/presentation has } \\
\text { increased my understanding of the field. }\end{array}$ & 3.89 & N/A \\
\hline $\begin{array}{l}\text { The faculty presentations were helpful in increasing } \\
\text { my understanding of nanotechnology }\end{array}$ & 4.17 & N/A \\
\hline $\begin{array}{l}\text { Nanotechnology will play an important role in the } \\
\text { future }\end{array}$ & 4.61 & 4.1 \\
\hline
\end{tabular}

The highlights on the students' data over a sample of 25 students in the 2012 TLC with a nanotechnology theme is given below

1. $25 \%$ of the total students (6 out of 24) are from underrepresented groups.

2. Nearly $46 \%$ (11 out of 24 ) have decided to go to IUPUI to pursue nanotechnology and were motivated through advisors and school recruitment tools.

3. $62 \%$ of the students (15 out of 24 ) expect that the nanotechnology education will assist them with engineering and science curricula, prepare them for a nanotechnology career in industry, and prepare them with research, hands-on experience and software.

4. Nearly $63 \%$ (15 out of 24 ) would like to pursue the nanotechnology track.

The students in the nanotechnology-TLC also performed better, as evidenced by attending class more regularly, submitting more of the assignments, and attaining higher course grades. 


\subsection{Upper Elective Course within the Track}

The assessment data in Table III reflects the impact on the junior/senior students within the ECE, ME, BME, Physics, and Chemistry. Scores of 5 indicate that students "strongly agree," while a score of 1 indicates that they "strongly disagree". The scores shown in the table are higher compare to the scores of courses on the same level and disciplines at IUPUI. The data collected reflects the students' satisfaction of the course and shows how well it meets their expectations.

TABLE III: Junior/Senior Engineering/Science Student Feedback. The scores shown in the table are higher compare to the scores of courses on the same level and disciplines at IUPUI.

\begin{tabular}{|l|c|}
\hline \multicolumn{1}{|c|}{ Survey Questions } & Scores \\
\hline Course objectives were clearly stated & 4.2 \\
\hline Content was appropriate & 4.1 \\
\hline Assignments were appropriate & 4.3 \\
\hline Class presentations were well planned & 4.2 \\
\hline Instructors were helpful and easily accessible & 4.0 \\
\hline I enjoyed the multidisciplinary aspects of this course & 4.1 \\
\hline
\end{tabular}

The highlights on the students' data over a sample of 60 students in the Nanosystems Principals and Integrated Nanosystems Process \& Devices courses are given below

1. Nearly $85 \%$ did not have prior experience of writing research term papers and agreed that the term paper in the courses have helped them not only to understand a topic in depth but also improved their writing skills.

2. $90 \%$ agreed that integration of knowledge from science and engineering have help them in better understanding the topic and felt confidence to face the job interviews in companies that look for multidisciplinary graduates.

3. $55 \%$ of the students (12 out of 22) who were senior undergraduates in the class want to join graduate program and pursue research.

4. $83 \%$ of the students agreed that the courses have encouraged and prepared them to pursue a career or research in nanotechnology.

\section{Conclusions}

The developed curriculum/research in nanotechnology model have led to research publications and have graduated more than 100 undergraduate/graduate students in three year period. Enrollment in both undergraduate and graduate programs has been enhanced and the number of graduating students has increased. The nanotechnology track developed has proved success in all research and curriculum aspects. The elements of this model in curriculum, research, recruitment, and dissemination have contributed to the success of the model.

The TLC cohort was formed in fall 2011 and fall 2012. Students' response to survey questions indicates the positive impact of the new modes of instructions followed in the TLC courses. The 
impact of the TLC was observed in providing good understanding of the nanotechnology area to the freshmen students. Freshmen students in the nanotechnology-TLC performed better, as evidenced by attending class more regularly, submitting more of the assignments, and attaining higher course grades. The interests shown by students to the courses developed provide a preview for the forthcoming nanotechnology track while also contributing to the infrastructure of the graduate program.

The new courses developed for the nanotechnology track serve as technical electives for the traditional ECE and ME degree programs keeping the same overall required credit hours. The syllabi and the contents of the courses were developed by combining the research and teaching experiences of the faculty members at the IUPUI campus. Moreover, these new courses have also attracted students from different disciplines of sciences and engineering. Students' response to survey questions indicates the positive impact of the new modes of instructions followed in the track. Integration of knowledge from science and engineering has given students better pictures on how sciences sets of data were taken, and they are in supportive to the track ideas. All items of Table III are above the average data of traditional elective courses within the ECE and ME curriculum. Likewise, items of Table II show the impact of TLC on ECE/ME undergraduate students, pursuing the nanotechnology track. The instructions followed here have impacted the collaboration between engineering and science faculty and students. The integration of knowledge has been demonstrated in teamwork projects, term papers, poster presentations, and research experience. Since the start of this track, more than 60 students enroll in nanotechnology courses every year 25 students are pursuing the nanotechnology track from the freshman engineering. Within the last two years, more than 15 graduate students have pursued their research thesis in nanotechnology area, among them; three have been pursuing Ph.D.

\section{ACKNOWLEDGEMENTS}

The authors would like to acknowledge Dr. Ricardo Decca from the Department of Physics, Dr. Jian Xie from the Department of Mechanical Engineering, and Dr. Christopher Newman from the Department of Chemistry at IUPUI for their contribution in teaching and supervising research projects in nanotechnology for students pursuing this track. The development of the track was supported by National Science Foundation-Nanotechnology Undergraduate Education (NUE) grant 1042110.

\section{References:}

1. Zheng W., Shih H. R., Lozano K., Pei J. S., Kiefer K., and Ma X., “A Practical Approach to Integrating Nanotechnology Education and Research into Civil Engineering Undergraduate Curriculum,” J. Nano. Educ., vol. 1, pp. 22-33, 2009.

2. Mehta B. R., "Nano Education at Indian Institutes of Technology: A Status Report,” J. Nano. Educ., vol. 1, pp. 106-108, 2009.

3. Certificate in Nanotechnology and Nanoscience, George Mason University [Available: http:/cos.gmu.edu/academics/graduate/certificates/certificate-nanotechnology-and-nanoscience].

4. Drexel University - BSc Materials Engineering with Specialization Nanotechnology [Available: http://www.materials.drexel.edu/Students/Undergrad/Tracks/]. 
5. Hadjilogiou, J., "The Engineering Curriculum for 2020: Values, Variability, Improvement and Knowledge," 33rd Annual Frontiers in Education (FIE'03), vol. 3, pp.S3A19-26, 2003.

6. Rizkalla, M. E. and Yokomoto, C. F., "Design of a Course in Semiconductor Device that Emphasizes Integration of Knowledge," Proceedings of the 2001 American Society for Engineering Education Annual Conference

7. Yokomoto, C. F., Rizkalla, M. E., O’loughlin, C. l., El-sharkawy, M. A., and Lamm, N. P., "Developing A Motivational Freshman Course In Using The Principle of Attached Learning," Journal of Engineering Education, pp. 99-106, January 1999.

8. Rizkalla, M.E., Agarwal, M., Shrestha, S., Varahramyan, K, "Integration of Knowledge in Engineering/science Via Nanotechnology Programs," 118th ASEE Annual Conference and Exposition, Vancouver, BC, 26 -29 June 2011.

9. Integrated Nanosystems Development Institute (INDI), Indiana University-Purdue University Indianapolis, Indiana [Available: http://www.iupui.edu/ indi/index.php].

10. Center for Research and Learning, A Division of Office of the Vice Chancellor for Research, IUPUI [Available: http://crl.iupui.edu/].

11. Undergraduate Research Program, Center for Research and Learning, IUPUI [Available: http://crl.iupui.edu/programs/].

12. IUPUI Nanotechnology Discovery Academy, IUPUI [Available: www.crl.iupui.edu/nanotech.asp]. 